\title{
Clinging to survival: Critically Endangered Chapman's pygmy chameleon Rhampholeon chapmanorum persists in shrinking forest patches
}

\author{
Krystal A. Tolley, Colin R. Tilbury, Jessica M. da Silva, Gary Brown \\ Yankho Chapeta and Christopher V. Anderson
}

\begin{abstract}
The Critically Endangered Chapman's pygmy chameleon Rhampholeon chapmanorum is endemic to the low elevation rainforest of the Malawi Hills in southern Malawi. Much of this forest has been converted to agriculture and it was uncertain whether chameleon populations have persisted. We used current and historical satellite imagery to identify remaining forest patches and assess deforestation. We then surveyed forest patches for the presence of this chameleon, and assessed its genetic diversity and structure. We estimated that $80 \%$ of the forest has been destroyed since 1984, although we found extant populations of the chameleon in each of the patches surveyed. Differentiation of genetic structure was strong between populations, suggesting that gene flow has been impaired. Genetic diversity was not low, but this could be the result of a temporal lag as well as lack of sensitivity in the mitochondrial marker used. Overall, the impact of forest loss is assumed to have led to a large demographic decline, with forest fragmentation preventing gene flow.
\end{abstract}

Keywords Africa, Chapman's pygmy chameleon, extinction, habitat loss, Malawi, reptile, Rhampholeon chapmanorum, threatened species

KRYSTAL A. TOLLEY* (Corresponding author, (1) orcid.org/0000-0002-7778-1963) and JessiCA M. DA SILVA ${ }^{\dagger}$ (D) orcid.org/0000-0001-8385-1166) South African National Biodiversity Institute, Kirstenbosch Research Centre, Private Bag X7 Claremont 7735, Cape Town, South Africa. E-mail k.tolley@sanbi.org.za

Colin R. Tilbury Department of Botany \& Zoology, University of Stellenbosch, Stellenbosch, South Africa

Gary Brown Les Terrasses, Sainte Innocence, France

Yankho ChAPETA $\ddagger$ Museums of Malawi, Chichiri, Blantyre, Malawi

CHRISTOPHER V. ANDERSON (10 orcid.org/0000-0001-7411-3102) Department of Biology, University of South Dakota, Vermillion, USA

${ }^{*}$ Also at: School of Animal, Plant and Environmental Sciences, University of the Witwatersrand, Johannesburg, South Africa

†Also at: Department of Zoology, Centre for Ecological Genomics \& Wildlife Conservation, University of Johannesburg, Johannesburg, South Africa

¥Also at: Biological Sciences Department, Mzuzu University, Luwinga, Mzuzu, Malawi

Received 6 February 2020. Revision requested 18 May 2020

Accepted 22 September 2020. First published online 3 August 2021.

\section{Introduction}

O verall extinction risk for chameleons is substantially higher than the global average of c. $15 \%$ for squamate reptiles (Böhm et al., 2013), with 34\% of species categorized as threatened and $18 \%$ as Near Threatened (IUCN, 2019). Most threatened species are forest specialists, with habitat loss and degradation being the primary threat (Tolley et al., 2016). Given that forest chameleons are intolerant of transformed habitats, as forest is lost chameleon populations decline and become locally extinct. There are five Critically Endangered forest-living chameleon species in mainland Africa, all threatened by forest loss (IUCN, 2019). They inhabit small rainforest patches on mountain inselbergs that tend to have high endemicity (Menegon et al., 2008; Conradie et al., 2016; Gereau et al., 2016; Lyakurwa et al., 2019). Thus, the loss of forest patches results in the extinction of endemic species (e.g. Betts et al., 2017), including chameleons.

The Critically Endangered Rhampholeon chapmanorum is a small (3.5-5.5 cm body length), terrestrial chameleon endemic to the low elevation rainforest of the Malawi Hills near Nsanje in southern Malawi (Fig. 1, Plate 1). These mountains rise to c. $900 \mathrm{~m}$ and were once covered by dense rainforest, primarily on the eastern slopes between 700-900 m (Dowsett-Lemaire et al., 2001). At the time of the description of $R$. champanorum there were indications that substantial areas of forest were being lost (Tilbury, 1992). To safeguard the species, 37 individuals ( 24 females and 13 males) from the type locality in the Malawi Hills were released in 1998 in a forest patch at Mikundi, Malawi, c. $95 \mathrm{~km}$ to the north (Dowsett-Lemaire et al., 2001; Tilbury, 2018). Follow-up surveys at the release site in 2001 and 2012 confirmed the population was present (C.R. Tilbury, unpubl. data). However, given the apparent loss of forest in the species' natural range, it was uncertain whether the remaining forest fragments still contained viable populations (Tolley et al., 2014).

Rhampholeon chapmanorum is unlikely to inhabit transformed areas, and therefore forest degradation, fragmentation and loss would be expected to cause an overall demographic decline (e.g. Andrén, 1994), leading to local extinctions. Furthermore, the loss of connectivity between populations affects ecosystem functioning, disrupts metapopulations, reduces gene flow and increases genetic population structure even over small spatial scales. Thus, the 

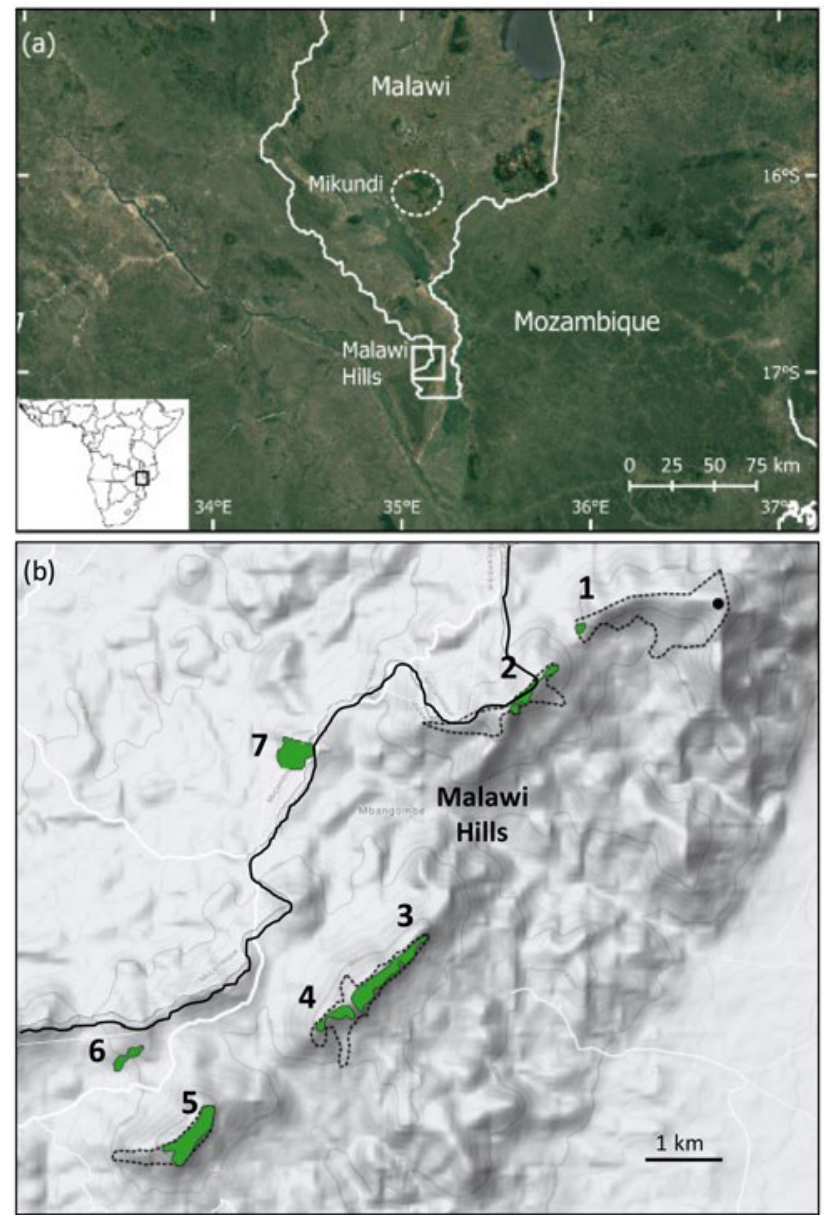

Fig. 1 (a) Overview map of sites searched for Rhampholeon chapmanorum. Broken circle shows the locality for Mikundi (exact locality obscured) and the square shows the Malawi Hills locality, and (b) forest patches in the Malawi Hills superimposed on a topographic map with contour lines. The present extent of forest patches is shaded, with the estimated extent in 1984/1985 shown by the dotted lines. Type locality is indicated by the black dot. Forest patches are numbered as in Table 1, except patches 6 and 7, which were not surveyed.

effect of habitat loss on the population is both direct (via population decline) and indirect because genetic diversity and gene flow are expected to diminish over time, reducing the adaptive potential of the population (Haddad et al., 2015; Leigh et al., 2019). The latter effects can be amplified in small populations because genetic drift is greater, leading to strong differentiation in genetic structure between populations, and inbreeding depression through fixation of deleterious alleles and elevated homozygosity, reducing resilience (Hanski, 2011). Information on population size, spatial genetic structure and diversity is therefore required to understand fully the extinction risk for R. chapmanorum.

To investigate these issues, we surveyed forest patches in both Malawi Hills and Mikundi, to assess whether R. chapmanorum populations are extant, quantified the extent of forest loss in the Malawi Hills using recent and

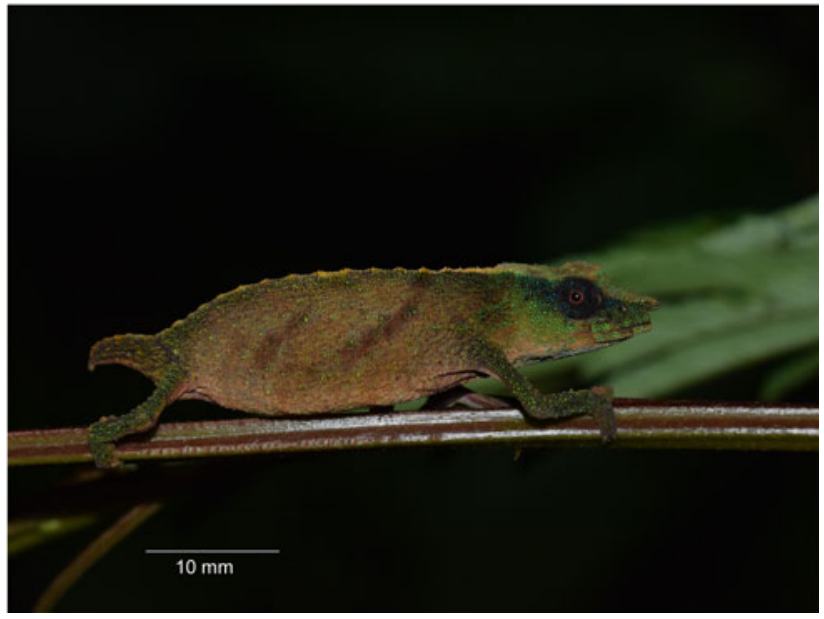

Plate 1 Male Rhampholeon chapmanorum in Mabunga forest.

historical satellite imagery as a proxy to gauge demographic decline, and examined the genetic structure and diversity of the populations. Because there are no historical baseline estimates of population size or genetic structure/diversity, we assume that demographic decline is proportional to forest loss. We predicted that fragmentation has disrupted gene flow, leading to strong differentiation of genetic structure and low genetic diversity.

\section{Methods}

We estimated the extent of forest loss using historical (1984/ 1985) and recent (2019) satellite imagery of Malawi Hills from Google Earth (Google, Mountain View, USA). Historical satellite images were of poor quality, and therefore images from both 1984 and 1985 were used. Polygons were created around each of the forest patches for these time periods, exported as $\mathrm{kmz}$ files, mapped in QGIS 2.18 (QGIS Development Team, 2016) and their areas quantified. The $700 \mathrm{~m}$ contour was used as a guide to assess where low elevation rainforest might have originally occurred (e.g. Dowsett-Lemaire et al., 2001).

Logistical constraints did not allow us to survey all the forest patches, but we were able to access two forest patches in the Malawi Hills and one at Mikundi, during 13-16 March 2016 (Fig. 1). We walked forest trails at night to record chameleons, using torchlight. Transects were defined by presence of trails and were therefore neither randomly chosen nor of a set distance or time. The location of each chameleon encountered was recorded $( \pm 3 \mathrm{~m})$ and a tissue sample was taken from a subset of adult chameleons (c. $2 \mathrm{~mm}$ tail clip) for genetic analysis. All individuals were returned to the same perch on which they were found.

To assess the genetic diversity within and between populations from each forest patch, an $845 \mathrm{bp}$ fragment of the $\mathrm{ND} 2$ mitochondrial gene was sequenced for 19 individuals. Genomic DNA was extracted using salt extraction (MacManes, 2008). ND2 was amplified in a PCR reaction 
TABLE 1 Forest patch areas in the Malawi Hills in 1984/1985 and 2019, with estimated extent lost. Patch numbers (in parentheses) correspond to the numbers in Fig. 1 b.

\begin{tabular}{lccc}
\hline Forest patch (no.) & $1984 / 1985$ (ha) & 2019 (ha) & \% lost \\
\hline Type locality/Chief's ancestors (1) & 88.5 & 1.2 & 98.6 \\
Patch 2 & 35.0 & 6.0 & 82.9 \\
Mwanambweli (3 \& 4) & 44.7 & 16.5 (patch 3), 5.25 (patch 4) & 51.3 \\
Mabunga (5) & 28.3 & 16.6 & 41.3 \\
Total & 196.5 & 45.55 & 76.8 \\
\hline
\end{tabular}

volume of $25 \mu$ with $0.4 \mu \mathrm{l}$ of $10 \mathrm{mM}$ dNTPs, $2.5 \mu \mathrm{l}$ of $25 \mathrm{mM}$ $\mathrm{MgCl}_{2}, 0.3 \mu \mathrm{l}$ of $10 \mathrm{pmol}$ forward (vMet2) and reverse (vTrp) primer (Cunningham \& Cherry, 2004), $2.5 \mu \mathrm{l}$ of $\mathrm{Mg}^{2+}$ free buffer solution, $0.15 \mu \mathrm{l}$ Taq polymerase, and 1-2 $\mu \mathrm{l}$ of $25 \mathrm{ng} / \mu \mathrm{l}$ DNA template. Thermal cycling included initial denaturation for $4 \mathrm{~min}$ at $95^{\circ} \mathrm{C}$ followed by 35 cycles denaturation for $45 \mathrm{~s}$ at $94{ }^{\circ} \mathrm{C}$, annealing for $45 \mathrm{~s}$ at $52{ }^{\circ} \mathrm{C}$, extension for $60 \mathrm{~s}$ at $72{ }^{\circ} \mathrm{C}$, and final extension for $10 \mathrm{~min}$ at $72{ }^{\circ} \mathrm{C}$. PCR products were run on a $1 \%$ agarose gel and visualized under a UV light to verify amplification. Amplicons were sequenced using the forward primer at Macrogen Inc. (Amsterdam, The Netherlands). Sequences were edited and aligned in Geneious R11 (Geneious, 2021) and deposited in GenBank (accession numbers: MT779023-MT779042). In addition, sequence from an individual originally sampled in 1998 from the type locality was available on GenBank (AY524919) for comparison.

Haplotype $(h)$ and nucleotide $(\pi)$ diversity for each locality was estimated (Tamura-Nei model of substitution, $\alpha=0.01$ ) using Arlequin 3.5 (Excoffier \& Lischer, 2010). A haplotype network was constructed using Network 5.0.1.1 (Bandelt et al., 1999; Polzin \& Daneschmand, 2003) to assess shared haplotypes between localities, including the two GenBank sequences from the type locality. To examine genetic structure between forest patches, an analysis of molecular variance (AMOVA) was run, estimating pairwise $\Phi_{\mathrm{ST}}$ in Arlequin.

\section{Results}

The satellite imagery showed that the forest extent in the Malawi Hills may have been c. 196 ha in 1984, in three patches (Table 1). As of 2019, the patches were much reduced, with two of the three patches fragmented into smaller patches totaling c. 40 ha, and the forest at the type locality completely cleared (Fig. 1). Currently, Mabunga forest is the largest intact patch (16.6 ha), having been reduced from 35 ha since 1984. Overall, we estimate c. $80 \%$ forest loss during 1984-2019. Given that the original extent (pre-1984) is not known, the magnitude of loss could have been greater as the original forest extent may have reached the lower slopes (e.g. Dowsett-Lemaire et al. 2001). There are also two additional low forest patches (at 550-620 m) on the western slopes of the Malawi Hills (13 and 3.9 ha; patches 6 and 7 , respectively, in Fig. 1), but it is unknown if they provide suitable habitat for chameleons.
We surveyed two of the five rainforest forest patches that were furthest apart. The first patch $(1.19 \mathrm{ha})$ is c. $1.8 \mathrm{~km}$ south-west of the type locality (Fig. 1; patch 1). Local community leaders indicated that the Chief's ancestors are buried in the forest, and it is considered sacred ground. We were therefore only permitted to survey along a footpath that skirted just inside the forest, where we recorded seven adult chameleons (six females, one male) during one evening. Although we were not permitted further inside this forest our observations of chameleons along the footpath suggest there is a population within the sacred forest, despite the small size of this patch. The second, Mabunga forest (Fig. 1; patch $5 ; 16.6 \mathrm{ha}$ ), is c. $7 \mathrm{~km}$ to the south-west of the first. We did not observe chameleons on the forest edge, but we recorded 10 individuals inside the forest along a footpath (seven females, three males) during one evening. Midway between the Chief's ancestors and Mabunga forests there are additional patches (Fig. 1; patches 2, 3 \& 4; the latter two at Mwanambweli forest) that we were not able to access, but given their location and extent, we assume there are chameleon populations present. Finally, we surveyed the forest patch at Mikundi (Fig. 1) where chameleons had been released in 1998 . We recorded 21 adult chameleons, plus 11 juveniles and hatchlings (body size $1.5-2.0 \mathrm{~cm}$ ) during one evening, but we did not observe chameleons on the forest edge or outside the forest.

Estimates of genetic diversity for all populations were within the range considered normal compared to other chameleon and small-bodied reptile species (Table 2; cf. Hague \& Routman, 2016; Main et al., 2018; Rutherford et al., 2019). There were no shared haplotypes between forest patches, including those previously sequenced from the original at the type locality (Fig. 2). Similarly, the AMOVA showed a significant difference between each of the forest patches $\left(\Phi_{S T}=0.23\right.$, $\mathrm{P}<0.001$ ) suggesting strong differentiation of genetic structure between populations and reduced gene flow across the relatively small distances between the patches surveyed in the natural range (Table 3).

\section{Discussion}

Although populations of $R$. chapmanorum persist in the Malawi Hills, the forest extent has been significantly reduced to a total of c. 40 ha. We can confirm there are extant 
TABLE 2 Genetic diversity estimates $( \pm \mathrm{SD})$ for Rhampholeon chapmanorum from three forest patches, showing haplotype diversity $h$, nucleotide diversity $\pi$ and number of haplotypes $H$. Patch numbers (in parentheses) correspond to the numbers in Fig. $1 b$.

\begin{tabular}{lllll}
\hline Forest patch (no.) & $\mathrm{n}$ & $h \pm \mathrm{SD}$ & $\pi \pm \mathrm{SD}$ & $H$ \\
\hline Chief s ancestors forest (1) & 6 & $0.800 \pm 0.172$ & $0.003 \pm 0.0021$ & 4 \\
Mabunga (5) & 9 & $0.722 \pm 0.159$ & $0.002 \pm 0.0014$ & 5 \\
Mikundi (released population) & 4 & $0.833 \pm 0.222$ & $0.014 \pm 0.0098$ \\
\hline
\end{tabular}

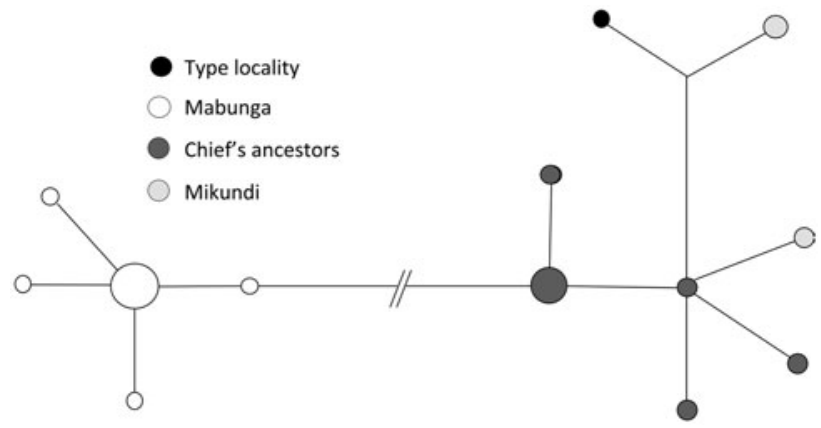

FIG. 2 Haplotype network for R. chapmanorum with haplotypes shaded according to locality where chameleons were sampled. Branch lengths are proportional to the number of mutations and circle size is proportional to the number of individuals with that haplotype.

TABLE 3 Pairwise analysis of molecular variance for $R$. chapmanorum from three forest patches, with $\Phi_{\mathrm{ST}}$ values (bottom matrix) and $P$ values (top matrix). Patch numbers (in parentheses) correspond to the numbers in Fig. 1 b.

\begin{tabular}{llll}
\hline & $\begin{array}{l}\text { Chief s } \\
\text { ancestors (1) }\end{array}$ & Mabunga (5) & Mikundi \\
\hline Chiefs ancestors (1) & & $<0.010$ & $<0.001$ \\
$\begin{array}{l}\text { Mabunga (5) } \\
\text { Mikundi }\end{array}$ & 0.088 & & $<0.001$ \\
\hline
\end{tabular}

populations in at least two of the five forest patches at higher elevations, and we assume the other higher elevation patches also hold populations. There are two patches at lower elevation that we did not survey, and we cannot assume that $R$. chapmanorum populations are present there, given these are below $700 \mathrm{~m}$ and low elevation rainforest was not considered to have occurred there (Dowsett-Lemaire et al., 2001). Chameleons were not observed outside forest although observations at the sacred forest were made at slightly degraded forest edge. Rhampholeon species are forest specialists (Branch et al., 2014) and cannot tolerate transformed habitats, so where forest has been destroyed, the populations will have gone locally extinct (as in the type locality). Conversely, chameleons appear to be abundant at the Mikundi release site, with chameleons of all age classes observed.

From aerial photography, the extent of the Malawi Hills forest was previously estimated to be c. 400 ha
(Dowsett-Lemaire \& Dowsett, 1988). This is approximately double our estimate of 196 ha for 1984, but the date of the aerial photographs used was not indicated. If the low elevation rainforest covered the mountain down to $700 \mathrm{~m}$ (Dowsett-Lemaire et al., 2001) the forest extent could have been 1,050 ha historically. Although speculative, this could mean that $96 \%$ of the original forest has been lost. Our estimate of a minimum of $80 \%$ forest loss since the mid $1980 \mathrm{os}$ is likely to have resulted in a similar decline of R. chapmanorum, or at least a dramatic population decline over at least 35-40 years. Despite this, genetic diversity is not low, but this can be explained by the lack of a linear relationship between genetic diversity and population declines that result from habitat loss (Pflüger et al., 2019). Erosion of genetic diversity at detectable levels has a long time lag that is influenced by the effective population size, the number of generations and the degree of habitat loss and fragmentation (e.g. Tilman et al., 1994; Krauss et al., 2010; Hoban et al., 2014; Wu et al., 2020). Conversely, genetic structure responds more rapidly to habitat fragmentation (Keyghobadi et al., 2005; Pflüger et al., 2019) because gene flow is impeded by isolation of local patches (Balkenhol et al., 2013). Populations of $R$. chapmanorum do not have reduced genetic diversity but they do have strong differentiation of genetic structure, with no shared haplotypes despite the short distance between them. This indicates that gene flow has been disrupted over a scale of just a few kilometres and that the metapopulation is not intact, increasing extinction risk.

Individuals from the released population at Mikundi are in the same haplotype group as those from the type locality and the Chief s ancestors sacred forest, although the haplotypes occur at different frequencies. Given that the original released population was small, the observed difference is probably the result of a founder effect in which the released individuals were not a random sample of the range of haplotypes in the original population. This can result in haplotype frequency differences between the new and source populations, and the effect can be magnified over time as genetic drift changes the proportions of haplotypes. In this case, assuming the generation time of Rhampholeon is 1-1.5 years, there would have been 15-20 generations since the release, which is sufficient time for genetic drift to have differentiated the populations given the small founding population.

Overall, our findings indicate there has been a severe demographic decline with disruption of gene flow as a result 
of extreme forest loss. The effects of this decline have yet to be fully manifested in the genetic composition, as genetic diversity and differentiation can continue to be negatively affected for many generations after habitat loss is halted, even with subsequent population size increases (Pflüger et al., 2019). The genetic differentiation shows that gene flow has already been disrupted, and the forest loss requires immediate attention to prevent further loss of genetic diversity. Urgent conservation action is needed, including halting of forest destruction and recovery of habitat to promote connectivity. Although part of the Malawi Hills falls within a Key Biodiversity Area (Matandwe Forest Reserve) most of the forest falls outside the reserve boundary (c.f. BirdLife International, 2020), and the effectiveness of the forest reserve is questionable, given that most of the destruction has been within its boundaries. Although extending the reserve to encompass all the forest patches would be a first step, measures are needed to avert the destruction of the remaining patches. In addition to $R$. chapmanorum, other endemic species could occur there, which would add weight to the need to conserve the remaining patches. Unfortunately, few surveys have been carried out in the area, with only widespread species of plants, birds and butterflies recorded (Dowsett-Lemaire et al., 2001).

A species action plan that defines conservation activities is urgently needed for R. chapmanorum. However, both the planning and the recommended actions require strong leadership, personnel, stakeholder engagement, including with government departments, and sufficient funding to ensure success. Many international organizations support the production and execution of species action plans (e.g. IUCN Species Survival Commission, WWF) and the involvement of these or analogous organizations will be essential to prevent the extinction of this species in the wild.

Acknowledgements We thank the Museums of Malawi for assisting with logistics and facilitating permits for this work; the South African National Biodiversity Institute for support; and for funding, the Scion Natural Science Association and the numerous contributors to crowd-source funding at Rockethub.

Author contributions Project conceptualization, sourcing of funding: KAT, CVA; field work, analysis: KAT; field work, planning: CRT, GB, YC; laboratory work, analysis: JMDS; writing: KAT, with assistance from all authors.

\section{Conflicts of interest None.}

Ethical standards This project abided by the ethical standards of Oryx, and the ethical guidelines of the British Herpetological Society (2017). Research was carried out under clearance from the South African National Biodiversity Institute (\#0001-2015), under agreement with the Museums of Malawi, Blantyre, a permit from the Malawian Department of Forestry-Forestry Research Institute, Zomba (14 January 2016), and permission from the Malawian Department of National Parks and Wildlife, endorsed by the Malawian National Commission for Science and Technology, Lilongwe (22 December 2015).

\section{References}

Andrén, H. (1994) Effects of habitat fragmentation on birds and mammals in landscapes with different proportions of suitable habitat: a review. Oikos, 71, 355-366.

Balkenhol, N., Pardini, R., Cornelius, C., Fernandes, F. \& Sommer, S. (2013) Landscape-level comparison of genetic diversity and differentiation in a small mammal inhabiting different fragmented landscapes of the Brazilian Atlantic Forest.

Conservation Genetics, 14, 355-367.

Bandelt, H.-J., Forster, P. \& Röhl, A. (1999) Median-joining networks for inferring intraspecific phylogenies. Molecular Biology \& Evolution, 16, 37-48.

Betts, M.G., Wolf, C., Ripple, W.J., Phalan, B., Millers, K.A., DuArte, A. et al. (2017) Global forest loss disproportionately erodes biodiversity in intact landscapes. Nature, 547, 441.

Bird Life International (2020) World Database of Key Biodiversity Areas. keybiodiversityareas.org [accessed 6 February 2020].

Böhm, M., Collen, B., Baillie, J.E., Bowles, P., Chanson, J., Cox, N. et al. (2013) The conservation status of the world's reptiles. Biological Conservation, 157, 372-385.

Branch, W.R., Bayliss, J. \& Tolley, K.A. (2014) Pygmy chameleons of the Rhampholeon platyceps complex (Squamata: Chamaeleonidae): description of four new species from isolated 'sky islands' of northern Mozambique. Zootaxa, 3814, 1-36.

British Herpetological Society (2017) British Herpetological Society: ethical policy and guidelines. The Herpetological Bulletin $141,46-48$.

Conradie, W., Bittencourt-Silva, G.B., Engelbrecht, H.M., Loader, S.P., Menegon, M., Nanvonamuquitxo, C. et al. (2016) Exploration of the hidden world of Mozambique's sky island forests: new discoveries of reptiles and amphibians. Zoosystematics \& Evolution, 92, 163-180.

Cunningham, M. \& Cherry, M.I. (2004) Molecular systematics of African 20-chromosome toads (Anura: Bufonidae). Molecular Phylogenetics \& Evolution, 32, 671-685.

Dowsett-Lemaire, F. \& Dowsett, R.J. (1988) Threats to the evergreen forests of southern Malawi. Oryx, 22, 158-162.

Dowsett-Lemaire, F., Dowsett, R.J. \& Dyer, M. (2001) Malawi. In Important Bird Areas in Africa and Associated Islands: Priority Sites for Conservation (eds L.D.C. Fishpool \& M.I. Evans), pp. 539-555. Pisces Publications, Newbury, \& BirdLife International, Cambridge, UK.

Excoffier, L. \& Lischer, H.E.L. (2010) Arlequin suite version 3.5: A new series of programs to perform population genetics analyses under Linux and Windows. Molecular Ecology Resources, $10,564-567$.

Geneious (2021) geneious.com [accessed 18 June 2021].

Gereau, R.E., Cumberlidge, N., Hemp, C., Hochirirch, A., Jones, T., KARIUKI, M. et al. (2016) Globally threatened biodiversity of the Eastern Arc mountains and coastal forests of Kenya and Tanzania. Journal of East African Natural History, 105, 115-201.

Haddad, N.M., Brudvig, L.A., Clobert, J., Davies, K.F., Gonzalez, A., Holt, R.D. et al. (2015) Habitat fragmentation and its lasting impact on Earth's ecosystems. Science Advances, 1 , e1500052.

Hague, M.T.J. \& Routman, E.J. (2016) Does population size affect genetic diversity? A test with sympatric lizard species. Heredity, $116,92-98$.

HANSKI, I. (2011) Habitat loss, the dynamics of biodiversity, and a perspective on conservation. Ambio, 40, 248-255.

Hoban, S., Arntzen, J., Bruford, M.W., Godoy, J.A., Hoelzel, A.R., Segelbacher, G. et al. (2014) Comparative evaluation of 
potential indicators and temporal sampling protocols for monitoring genetic erosion. Evolutionary Applications, 7, 984-998.

IUCN (2019) The IUCN Red List of Threatened Species. iucnredlist.org [accessed 6 February 2020].

Keyghobadi, N., Roland, J., Matter, S.F. \& Strobeck, C. (2005) Among-and within-patch components of genetic diversity respond at different rates to habitat fragmentation: an empirical demonstration. Proceedings of the Royal Society B: Biological Sciences, 272, 553-560.

Krauss, J., Bommarco, R., Guardiola, M., Heikinen, R.K., Helm, A., KuUssaari, M. et al. (2010) Habitat fragmentation causes immediate and time-delayed biodiversity loss at different trophic levels. Ecology Letters, 13, 597-605.

Leigh, D.M., Hendry, A.P., Vázquez-Domínguez, E. \& Friesen, V.L. (2019) Estimated six per cent loss of genetic variation in wild populations since the industrial revolution. Evolutionary Applications, 12, 1505-1512.

Lyakurwa, J.V., Howell, K.M., Munishi, L.K. \& Treydte, A.C. (2019) Uzungwa Scarp Nature Forest Reserve: a unique hotspot for reptiles in Tanzania. Acta Herpetologica, 14, 3-14.

MacManes, M. (2008) MacManes Salt Extraction Protocol. Museum of Vertebrate Zoology Evolutionary Genetics Lab, Berkeley, USA. mvz.berkeley.edu/egl/protocols/extraction/MacManesSaltExtraction [accessed 18 January 2021].

Main, D.C., van Vuuren, B.J. \& Tolley, K.A. (2018) Cryptic diversity in the common flap-necked chameleon Chamaeleo dilepis in South Africa. African Zoology, 53, 11-16.

Menegon, M., Doggart, N. \& Owen, N. (2008) The Nguru Mountains of Tanzania, an outstanding hotspot of herpetofaunal diversity. Acta Herpetologica, 3, 107-127.
Pflüger, F.J., Signer, J. \& Balkenhol, N. (2019) Habitat loss causes non-linear genetic erosion in specialist species. Global Ecology and Conservation, 17, e00507.

Polzin, T. \& Daneschmand, S.V. (2003) On Steiner trees and minimum spanning trees in hypergraphs. Operations Research Letters 31, 12-20.

QGiS Development Team (2016) QGIS. Open Source Geospatial Foundation Project. qgis.osgeo.org [accessed 30 April 2016].

Rutherford, E.M., Ontano, A., Kantor, C. \& Routman, E.J. (2019) Genetic variation across trophic levels: a test of the correlation between population size and genetic diversity in sympatric desert lizards. PLOS ONE, 14, e0224040.

Tilbury, C.R. (1992) A new dwarf forest chameleon from Malawi. Tropical Zoology, 5, 1-9.

Tilbury, C.R. (2018) Chameleons of Africa: An Atlas, Including the Chameleons of Europe, the Middle East and Asia. 2nd edition. Edition Chimaira, Frankfurt, Germany.

Tilman, D., May, R.M., Lehman, C.L. \& NowaK, M.A. (1994) Habitat destruction and the extinction debt. Nature, 371, 65-66.

Tolley, K.A., Alexander, G.J., Branch, W.R., Bowles, P. \& Maritz, B. (2016) Conservation status and threats for African reptiles. Biological Conservation, 204, 63-71.

Tolley, K.A., Menegon, M. \& Plumptre, A. (2014) Rhampholeon chapmanorum. In The IUCN Red List of Threatened Species 2014. dx.doi.org/10.2305/IUCN.UK.2014-3.RLTS.T172568A1345654.en [accessed 17 October 2019].

Wu, Y., Chen, Y., Chang, S.C., Chen, Y.F. \& Shen, T.J. (2020) Extinction debt in local habitats: quantifying the roles of random drift, immigration and emigration. Royal Society Open Science, 7, 191039 . 